WOMEN'S SEXUAL HEALTH

\title{
Deep Dyspareunia and Sexual Quality of Life in Women With Endometriosis
}

Leona K. Shum, BSc(Hons), Mohamed A. Bedaiwy, MD, PhD, 2,3,4,5 Catherine Allaire, MD, 2,3

Christina Williams, MD, ${ }^{2,3}$ Heather Noga, MA, ${ }^{4}$ Arianne Albert, $\mathrm{PhD},{ }^{2,4}$ Sarka Lisonkova, MD, $\mathrm{PhD},{ }^{2,5}$ and

Paul J. Yong, MD, PhD $2,3,4,5$

\section{ABSTRACT}

Introduction: Deep dyspareunia occurs in half of women with endometriosis, a condition present in $10 \%$ of reproductive-age women and associated with negative effects on sexual quality of life (SQoL). However, women with endometriosis can have other clinical factors (eg, superficial dyspareunia, other pelvic pains, and psychological or pain conditions) possibly affecting SQoL.

Aims: To determine whether deep dyspareunia is associated with SQoL in women with endometriosis, independent of potential confounders.

Methods: This study involved a prospective patient registry of women at a tertiary-level referral center for endometriosis and pelvic pain. Inclusion criteria were (i) referrals to the center recruited into the registry from January 2014 through December 2016 and (ii) subsequent surgery at the center with histologic confirmation of endometriosis. Exclusion criteria included menopausal status, age at least 50 years, never sexually active, or did not answer dyspareunia or SQoL questions. Bi-variable tests and multiple linear regression analysis were performed.

Main Outcome Measures: SQoL measured by the 5-item sexual intercourse subscale of the Endometriosis Health Profile-30 (EHP-30) modular questionnaire (0-100\%, with higher scores indicating worse SQoL).

Results: Consent rate for the prospective registry was $87 \% ; 277$ women met the study criteria (mean age $=34.2$ \pm 7.1 years). Most women had stage I to II endometriosis at time of surgery (64\%), with the remaining having stage III to IV endometriosis. Through regression analysis, worse SQoL (higher EHP-30 sexual intercourse subscale score) was independently associated with: more severe deep dyspareunia $(P<.0001)$, more severe superficial dyspareunia $(P<.0001)$, increased depression $(P<.001)$, higher pain catastrophizing $(P=.04)$, bladder pain syndrome $(P=.02)$, heterosexual orientation $(P<.001)$, and new referral status $(P=.02)$.

Conclusion: In women with endometriosis at a tertiary referral center, more severe deep dyspareunia was associated with worse SQoL, independent of superficial dyspareunia, psychological comorbidities, and other potential confounders. Shum LK, Bedaiwy MA, Allaire C, et al. Deep Dyspareunia and Sexual Quality of Life in Women With Endometriosis. Sex Med 2018;6:224-233.

Copyright ( 2018, The Authors. Published by Elsevier Inc. on behalf of the International Society for Sexual Medicine. This is an open access article under the CC BY-NC-ND license (http://creativecommons.org/licenses/by-nc-nd/4.0/).

Key Words: Deep Dyspareunia; Endometriosis; Sexual Quality of Life; Superficial Dyspareunia

\section{INTRODUCTION}

Dyspareunia is pain with penetration during sexual activity. ${ }^{1}$ Dyspareunia is most commonly classified as superficial

Received January 10, 2018. Accepted April 13, 2018.

'School of Population and Public Health, University of British Columbia, Vancouver, BC, Canada;

2Department of Obstetrics and Gynaecology, University of British Columbia, Vancouver, BC, Canada;

${ }^{3}$ BC Women's Center for Pelvic Pain and Endometriosis, Vancouver, BC, Canada; dyspareunia or deep dyspareunia. ${ }^{2}$ Superficial dyspareunia refers to pain at initial entry of the vagina (perceived in the vulvar region and/or vaginal introitus), whereas deep dyspareunia is pain

\footnotetext{
${ }^{4}$ Women's Health Research Institute, Vancouver, BC, Canada;

${ }^{5}$ BC Children's Hospital Research Institute, Vancouver, BC, Canada

Copyright (c) 2018, The Authors. Published by Elsevier Inc. on behalf of the International Society for Sexual Medicine. This is an open access article under the CC BY-NC-ND license (http://creativecommons.org/ licenses/by-nc-nd/4.0/).

https://doi.org/10.1016/j.esxm.2018.04.006
} 
associated with deep penetration (perceived in the vaginal canal or pelvic region). ${ }^{2}$ Quality of life (QoL) and relationships of women are significantly affected by the presence of dyspareunia.

Deep dyspareunia is often associated with endometriosis, which is a common and chronic gynecologic disease in women. ${ }^{5,6}$ In fact, endometriosis is one of the main causative factors of deep dyspareunia. ${ }^{6}$ Endometriosis is defined as the growth of endometrial tissue outside the uterus ${ }^{7}$ and affects an estimated $10 \%$ of reproductive-age women. ${ }^{8}$ Other symptoms of endometriosis include dysmenorrhea (menstrual pain), dyschezia (painful defecation), and chronic pelvic pain. ${ }^{4}$ The pathophysiology of deep dyspareunia in endometriosis is complex and can include direct effects of the endometriotic lesions, concurrent diagnoses (eg, depression or interstitial cystitis or bladder pain syndrome), and/or central sensitization. ${ }^{\text {? }}$

Women with endometriosis and deep dyspareunia have been found to have lower sexual QoL (SQoL) such as sexual functioning and satisfaction. ${ }^{5,10}$ Previous studies also have shown that women with endometriosis and deep dyspareunia experience worse sexual functioning than women without endometriosis. ${ }^{4,11,12}$ Such women report decreases in number and quality of coituses, overall sexual activity, self-esteem, and sexual satisfaction. ${ }^{3,12,13}$ Women also can develop negative thoughts about intercourse and might avoid sexual activity altogether, which can negatively affect personal relationships. ${ }^{12,14,15}$

However, when considering the relation between deep dyspareunia and SQoL in women with endometriosis, it is important to consider potential confounders. For example, women with endometriosis (and deep dyspareunia) can have other types of pelvic pain, psychological comorbidities, and concurrent pain diagnoses. Moreover, it is possible for a patient to have concurrent deepsuperficial dyspareunia, for example, in women with endometriosis and vulvodynia. ${ }^{2}$ Superficial dyspareunia from vulvodynia, particularly provoked vestibulodynia, has been well documented to affect sexual functioning and distress. ${ }^{16}$ Thus, concurrent superficial dyspareunia is another important consideration when assessing the relation between deep dyspareunia and SQoL.

The Endometriosis Health Profile (EHP-30) is a validated and reliable questionnaire that measures health-related $\mathrm{QoL}$ in women with endometriosis. ${ }^{14,17}$ Test-retest reliability, content validity, and construct validity have been assessed in the EHP$30 .{ }^{14,18}$ The EHP-30 is composed of a core questionnaire of 30 items, in addition to 6 modular parts containing 23 items. ${ }^{14} 1$ of the 6 modular parts specifically addresses sexual intercourse, which includes questions about pain, guilt, worry, frustration, and avoidance associated with sexual intercourse.

The objective of this study was to determine whether deep dyspareunia was independently associated with a worse SQoL (measured by the EHP-30) in women with endometriosis, controlling for potential confounders such as superficial dyspareunia, other types of pelvic pain, and other comorbidities. It was hypothesized that deep dyspareunia would be associated with a worse SQoL independent of superficial dyspareunia and other potential confounders.

\section{METHODS}

\section{Study Setting}

This study involved a prospective patient registry of women, the Endometriosis and Pelvic Pain Prospective Interdisciplinary Cohort (EPPIC; ClinicalTrials.gov, NCT02911090), at a tertiary-level referral center. ${ }^{19}$ This registry uses the Research Electronic Data Capture online database (REDCap), which has been previously described in detail. ${ }^{20,21}$ The registry was designed with the intent of analyzing factors associated with pain and QoL measures at baseline and at annual follow-up for women with endometriosis and pelvic pain. The registry has an $87 \%$ consent rate among referrals to the center.

\section{Ethics Approval}

The prospective registry was approved by the research ethics board of the University of British Columbia (Vancouver, BC, Canada; H16-00264).

\section{Inclusion and Exclusion Criteria}

Inclusion criteria were (i) recruitment into the registry among referrals to the center from January 2014 to December 2016 and (ii) subsequent surgery at the center (after recruitment into the registry) with pathologic confirmation of endometriosis $(\geq 1$ histologically positive biopsy result). Exclusion criteria were (i) age younger than 18 years; (ii) age at least 50 years or menopausal status because endometriosis resolves after menopause and to lessen genitourinary syndrome of menopause as a concurrent factor $^{22}$; (iii) no intake physical examination (eg, because of severe vaginismus); (iv) never sexually active; and (v) did not answer the dyspareunia questions or complete the EHP-30 modular intercourse subscale as part of the registry data collection. The study population flowchart is presented in Figure 1.

\section{Primary Outcome (SQoL, EHP-30 Intercourse Subscale]}

The primary outcome was SQoL as measured by the 5-item subscale of the EHP-30 sexual intercourse modular questionnaire. This particular subscale assesses pain with intercourse, worry about having intercourse because of the pain, guilt about not wanting intercourse, frustration about not enjoying intercourse, and avoidance of sexual intercourse. ${ }^{14}$ Each of the 5 questions was answered on a 5 -point Likert scale $(0=$ never, $1=$ rarely, $2=$ sometimes, $3=$ often, $4=$ always). Patient scores were summed together, divided by the maximum total score of 20 , and then multiplied by 100 to give a percentage $\left(\sum / 20 \times 100 \%\right)$, where $0 \%$ indicates the best SQoL and 100\% indicates the worst SQoL. ${ }^{14,18}$

\section{Potentially Associated Factors}

Pain severities, psychological comorbidities, pain diagnoses, and demographic and behavioral factors are potential factors 


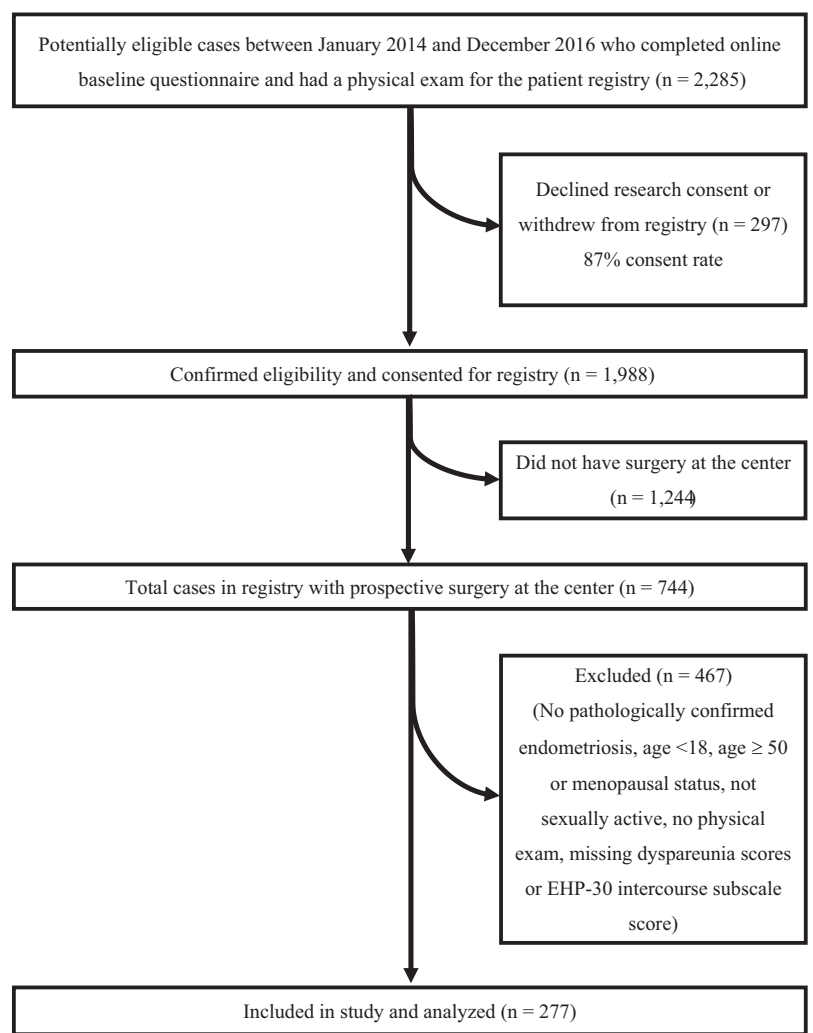

Figure 1. Study population flowchart indicating the inclusion and exclusion criteria for this study. EHP-30 = Endometriosis Health Profile-30.

associated with SQoL and were available as part of the patient registry data collection. All variables were assessed at intake into the registry through a baseline patient-reported online questionnaire, gynecologist examination, and/or review of medical records and prospectively entered into the registry. The only exception was surgical data collection, which was prospectively entered into the registry at the subsequent surgery at the center (after baseline), according to the recommendations of the Endometriosis Phenome and Biobanking Harmonisation Project (EPHect) of the World Endometriosis Research Foundation. ${ }^{23}$

Deep dyspareunia was measured on a numeric rating scale from 0 (no pain) to 10 (worst pain imaginable). Other pain severities included superficial dyspareunia, dysmenorrhea, dyschezia, back pain, and chronic pelvic pain, also on a numeric rating scale from 0 to 10 . The wording of these questions has been previously published. ${ }^{20}$ For deep dyspareunia, the wording was "How painful was deep penetration during sexual activity?" For superficial dyspareunia, the wording was "How painful was initial penetration (entry) during sexual activity?”

All psychological comorbidities were assessed using validated standardized questionnaires. The Patient Health Questionnaire (PHQ-9) was used for depression. The PHQ-9 includes 9 questions that assess the severity of depression symptoms; each question is rated from 0 (not at all) to 3 (nearly every day) for a total score up to $27 .{ }^{24}$ For anxiety, the Generalized Anxiety
Disorder (GAD-7) questionnaire was used to assess the severity of anxiety symptoms through a set of 7 questions, each rated from 0 (not at all) to 3 (nearly every day) for a total score up to 21. ${ }^{25}$ The Pain Catastrophizing Scale (PCS) is composed of 13 questions that assess magnification, rumination, and helplessness; each question is rated from 0 (not at all) to 4 (all the time) for a total score up to $52 .{ }^{26}$

Pain diagnoses included pelvic floor myalgia (levator ani tenderness), abdominal wall pain diagnosed by the Carnett test (abdominal tenderness that worsens when abdominal muscles are contracted), ${ }^{27}$ irritable bowel syndrome clinically diagnosed through the Rome III criteria, ${ }^{28}$ and bladder pain syndrome clinically diagnosed using the criteria as defined by the American Urological Association or the International Continence Society. ${ }^{29,30}$

Demographic and behavioral factors included age, ethnicity (Caucasian vs other ethnicity), body mass index, referral type (new referral vs rereferral), hormonal therapy use (currently using vs not currently using), sexual orientation (heterosexual vs other), previous surgical diagnosis of endometriosis, previous hysterectomy, abuse as a child by sexual touch or sexual threat (using selected questions from the Childhood Trauma Questionnaire), ${ }^{31}$ sexual assault as an adult, pregnancy history, smoking habits, alcohol consumption, current marital status (married vs not married), education (some high school, graduated high school or earned Graduate Equivalency Diploma, some college, graduated 2-year college, graduated 4-year college, postgraduate degree, other education), and income $(<\$ 20,000$, $\$ 20,000-39,999, \quad \$ 40,000-59,999, \quad \$ 60,000-79,999$, $\$ 80,000-99,999, \geq \$ 100,000)$.

As part of the inclusion criteria of the study, endometriosis had to be pathologically confirmed at the time of subsequent surgery at the center (after recruitment into the registry). Endometriosis was prospectively staged through calculation of the American Society of Reproductive Medicine score and classified as stage I to II or stage III to IV. ${ }^{32}$

\section{Statistical Analyses}

Pairwise comparisons between the primary outcome (SQoL measured by the EHP-30 intercourse subscale, 0-100\%) and each potentially associated variable were conducted. Spearman rank correlation was used for continuous variables, MannWhitney U-test was used for binary variables, and KruskalWallis test was used for categorical predictors with at least 3 levels. All variables that were found to have a statistically significant association $(P<.05)$ with the primary outcome were used in multiple linear regression analysis.

In multiple linear regression models, the Akaike information criterion was used in an automated stepwise model building technique with a statistical significance of 0.05 to obtain the most parsimonious model. ${ }^{33}$ To validate the model, 2 other model building techniques were conducted: sequential backward elimination and multi-model inference. In the sequential backward elimination technique, the variable with the largest $P$ value 
Table 1. Demographics of study population $(\mathrm{N}=277)^{*}$

\begin{tabular}{|c|c|}
\hline Variable & $\begin{array}{l}\text { Mean } \pm \text { SD or } \\
\text { count }(\%)\end{array}$ \\
\hline Age $(y)$ & $34.2 \pm 7.1$ \\
\hline BMl $\left(\mathrm{kg} / \mathrm{m}^{2}\right)$ & $24.9 \pm 5.0$ \\
\hline \multicolumn{2}{|l|}{ Ethnicity } \\
\hline Caucasian & $200(72.2 \%)$ \\
\hline Other ethnicity & 77 (27.8\%) \\
\hline EHP-30 intercourse subscale score, \% & $60.9 \pm 28.3$ \\
\hline Deep dyspareunia severity (0-10) & $6.5 \pm 2.8$ \\
\hline Superficial dyspareunia severity (0-10) & $3.9 \pm 3.1$ \\
\hline Dyschezia severity (0-10) & $4.3 \pm 3.2$ \\
\hline Depression (PHQ-9) score (0-27) & $9.3 \pm 7.0$ \\
\hline Anxiety (GAD-7) score (0-21) & $7.3 \pm 6.1$ \\
\hline Pain Catastrophizing Scale score (0-52) & $21.6 \pm 14.1$ \\
\hline Dysmenorrhea severity (0-10) & $8.0 \pm 2.2$ \\
\hline Chronic pelvic pain severity $(0-10)$ & $6.0 \pm 3.0$ \\
\hline Back pain severity $(0-10)$ & $5.7 \pm 3.0$ \\
\hline Irritable bowel syndrome & $152(54.9 \%)$ \\
\hline Bladder pain syndrome & 140 (50.5\%) \\
\hline $\begin{array}{l}\text { Abdominal wall pain (positive } \\
\text { Carnett test result) }\end{array}$ & $82(29.6 \%)$ \\
\hline Pelvic floor myalgia & $93(33.6 \%)$ \\
\hline \multicolumn{2}{|l|}{ ASRM endometriosis stage } \\
\hline $1-\|$ & 177 (63.9\%) \\
\hline III-IV & $97(35.0 \%)$ \\
\hline Missing & $3(1.1 \%)$ \\
\hline \multicolumn{2}{|l|}{ Hormonal therapy } \\
\hline Yes (currently using) & $45(16.2 \%)$ \\
\hline No (not currently using) & $232(83.8 \%)$ \\
\hline \multicolumn{2}{|l|}{$\begin{array}{l}\text { Previous surgery for endometriosis (before } \\
\text { recruitment to registry) }\end{array}$} \\
\hline Yes & $151(54.5 \%)$ \\
\hline No & $126(45.5 \%)$ \\
\hline \multicolumn{2}{|l|}{ Hysterectomy } \\
\hline Yes & $8(2.9 \%)$ \\
\hline No & 269 (97.1\%) \\
\hline \multicolumn{2}{|l|}{ Sexual orientation } \\
\hline Heterosexual & $265(95.7 \%)$ \\
\hline Other & $12(4.3 \%)$ \\
\hline \multicolumn{2}{|l|}{ Experience as a child ( $<14$ y old): sexual touch } \\
\hline Yes & $46(16.6 \%)$ \\
\hline No & 209 (75.5\%) \\
\hline Refused to answer & $22(7.9 \%)$ \\
\hline \multicolumn{2}{|l|}{ Experience as a child ( $<14$ y old): sexual threat } \\
\hline Yes & $10(3.6 \%)$ \\
\hline No & $244(88.1 \%)$ \\
\hline Refused to answer & $23(8.3 \%)$ \\
\hline \multicolumn{2}{|l|}{$\begin{array}{l}\text { Experience as an adult ( } \geq 14 \text { y old): sexual } \\
\text { assault }\end{array}$} \\
\hline Yes & $42(15.2 \%)$ \\
\hline No & $215(77.6 \%)$ \\
\hline Refused to answer & $20(7.2 \%)$ \\
\hline \multicolumn{2}{|l|}{ Married } \\
\hline Yes & $149(53.8 \%)$ \\
\hline
\end{tabular}

(continued)
Table 1. Continued

\begin{tabular}{|c|c|}
\hline Variable & $\begin{array}{l}\text { Mean } \pm \text { SD or } \\
\text { count }(\%)\end{array}$ \\
\hline No & 128 (46.2\%) \\
\hline \multicolumn{2}{|l|}{ Ever pregnant } \\
\hline Yes & 139 (50.2\%) \\
\hline No & 138 (49.8\%) \\
\hline \multicolumn{2}{|l|}{ Parity } \\
\hline Parous & 110 (39.7\%) \\
\hline Nulliparous & 167 (60.3\%) \\
\hline \multicolumn{2}{|l|}{ Education } \\
\hline Some high school & $7(2.5 \%)$ \\
\hline Graduated high school or earned CED & $26(9.4 \%)$ \\
\hline Some college & 65 (23.5\%) \\
\hline Graduated 2-y college & $37(13.4 \%)$ \\
\hline Graduated 4-y college & 81 (29.2\%) \\
\hline Postgraduate degree & $54(19.5 \%)$ \\
\hline Other & $7(2.5 \%)$ \\
\hline \multicolumn{2}{|l|}{ Income } \\
\hline$<\$ 20,000$ & $24(8.7 \%)$ \\
\hline$\$ 20,000-\$ 39,999$ & $41(14.8 \%)$ \\
\hline$\$ 40,000-\$ 59,999$ & 39 (14.1\%) \\
\hline$\$ 60,000-\$ 79,999$ & 59 (21.3\%) \\
\hline$\$ 80,000-\$ 99,999$ & 42 (15.2\%) \\
\hline$\geq \$ 100,000$ & 72 (26.0\%) \\
\hline \multicolumn{2}{|l|}{ Smoking } \\
\hline Yes & $34(12.3 \%)$ \\
\hline No & 243 (87.7\%) \\
\hline \multicolumn{2}{|l|}{ Alcohol consumption } \\
\hline Yes & 181 (65.3\%) \\
\hline No & 96 (34.7\%) \\
\hline \multicolumn{2}{|l|}{ Referral type } \\
\hline New & 226 (81.6\%) \\
\hline Rereferral & 51 (18.4\%) \\
\hline
\end{tabular}

ASRM = American Society for Reproductive Medicine; $\mathrm{BMI}=$ body mass index; EHP-30 = Endometriosis Health Profile-30; GAD-7 = Generalized Anxiety Disorder; GED = Graduate Equivalency Diploma; $\mathrm{PHQ}=$ Patient Health Questionnaire.

*277 informative observations for all considered variables except BMI (n = 275).

at each step was individually removed from the model until all variables left in the model had a $P$ value below the removal threshold $(P<.05) .{ }^{34}$ Multi-model inference was performed using established procedures that have been previously described in detail. ${ }^{35,36}$

All data analysis was performed using R 3.4.1 for Windows (R Foundation for Statistical Computing, Vienna, Austria). Statistical significance was set at an $\alpha$ value less than 0.05 . Mean values are provided alongside the SD. Missing values were excluded from all data analyses.

\section{Power Analysis}

In a previous retrospective study of 22 women, deep dyspareunia severity $(0-10)$ was found to be significantly correlated 
with SQoL measured by the EHP-30 (Spearman $r=0.45$, $P=.036$ ), which suggests that $99 \%$ power can be achieved by a sample size of 82 . Regardless of this power analysis, recent simulations suggest that for stability and accuracy of correlation coefficient estimates from observational data, a sample size of approximately 250 is optimal. ${ }^{37}$

\section{RESULTS}

\section{Patient Demographics}

277 women met the entire study criteria (Figure 1). Detailed characteristics of the study population are listed in Table 1 . The mean SQoL (EHP-30 intercourse subscale score) was $60.9 \%$, and the mean deep dyspareunia severity was 6.5 of 10 . Most women were Caucasian (72\%). Approximately half had irritable bowel syndrome or bladder pain syndrome, almost $1 / 3$ had abdominal wall pain (positive Carnett test result), and $1 / 3$ had pelvic floor myalgia. More than 2/3 of women were diagnosed with stage I to II endometriosis at subsequent surgery at the center, with the remaining diagnosed with stage III to IV endometriosis (Table 1).

\section{Pairwise Associations}

All pairwise associations between the primary outcome (SQoL measured by the EHP-30 intercourse subscale) and other variables are presented in Tables 2 and 3. Factors found to be significantly associated $(P<.05)$ with worse SQoL (higher EHP30 intercourse subscale score) were more severe pain scores for deep dyspareunia, superficial dyspareunia, dysmenorrhea, dyschezia, chronic pelvic pain, and back pain; younger age; increased depression (PHQ-9) and anxiety (GAD-7) symptoms; higher pain catastrophizing score (PCS); heterosexual orientation; lower education; presence of abdominal wall pain (positive Carnett test result); pelvic floor myalgia; stage of endometriosis; and bladder pain syndrome. Rereferral status was actually associated with improved SQoL (ie, new referrals had worse SQoL). Deep dyspareunia was found to have the greatest correlation with SQoL (Spearman $\rho=0.55$ ). A plot visualizing the relation between deep dyspareunia severity and worse SQoL (higher EHP-30 intercourse subscale score) is presented in Figure 2.

\section{Multiple Linear Regression}

All variables found to be significantly associated with the primary outcome through pairwise associations were considered for the multiple linear regression analysis. Using minimization of the Akaike information criterion, the final best-fit regression model indicated that the following variables were associated with worse SQoL (Table 4): more severe deep dyspareunia $(b=4.50$, $P<.0001)$, more severe superficial dyspareunia $(\mathrm{b}=1.92$, $P<.0001$ ), increased depression (PHQ-9; $\mathrm{b}=0.86, P<.001$ ), higher PCS score $(\mathrm{b}=0.22, P=.04)$, presence of bladder pain syndrome $(\mathrm{b}=5.69, P=.02)$, heterosexual orientation $(\mathrm{b}=$ 19.95, $P<.001)$, and referral type $(\mathrm{b}=-7.34, P=.02$;
Table 2. Continuous factors and sexual quality of life (EHP-30 intercourse subscale)*

\begin{tabular}{lcc}
\hline Variable & Spearman $\rho$ & $P$ value \\
\hline Deep dyspareunia severity (0-10) & 0.55 & $<.0001$ \\
Superficial dyspareunia severity (0-10) & 0.43 & $<.0001$ \\
Dysmenorrhea severity (0-10) & 0.15 & .013 \\
Dyschezia severity (0-10) & 0.28 & $<.0001$ \\
Chronic pelvic pain severity (0-10) & 0.24 & $<.0001$ \\
Back pain severity (O-10) & 0.21 & $<.001$ \\
Age (y) & -0.16 & .0082 \\
BMl (kg/m ${ }^{2}$ ) & -0.038 & .53 \\
Depression (PHQ-9) score (0-27) & 0.41 & $<.0001$ \\
Anxiety (CAD-7) score (0-21) & 0.37 & $<.0001$ \\
Pain Catastrophizing Scale score (0-52) & 0.36 & $<.0001$ \\
\hline
\end{tabular}

$\mathrm{BMI}=$ body mass index; EHP-30 = Endometriosis Health Profile-30; GAD$7=$ Generalized Anxiety Disorder; PHQ = Patient Health Questionnaire.

*277 informative observations for all considered variables except BMI $(n=275)$.

Table 4). The regression model was robust with the same model produced by sequential backward elimination and by the addition of back pain produced by multi-model inference (data not shown). ${ }^{35,36}$

\section{DISCUSSION}

In this analysis of a prospective patient registry of women with endometriosis, more severe deep dyspareunia was associated with worse SQoL. The association between deep dyspareunia and SQoL remained after controlling for other factors including superficial dyspareunia, other types of pelvic pain, psychological comorbidities, pain diagnoses, and demographic and behavioral factors. Also, endometriosis stage was found not to confound the association between deep dyspareunia and SQoL. The findings support that endometriosis-associated deep dyspareunia does independently affect a woman's SQoL.'

Strengths of this study include its prospective nature, because all patients prospectively underwent surgery at the center; therefore, staging of endometriosis was well documented and reflected disease that was present at the time of initial intake. Another strength of this study is the use of specific validated methods to assess psychological comorbidities (anxiety, depression, pain catastrophizing), clinically diagnosed pain conditions (irritable bowel syndrome, bladder pain syndrome, abdominal wall pain), and evaluation of the primary outcome, SQoL (EHP30). Our findings from multivariable analyses were robust because they were reproduced by 3 different model building techniques.

Limitations to this study include its observational character, which precludes conclusions about a possible effect of treatment of deep dyspareunia on improvement of SQoL. A randomized controlled trial is needed to provide causal evidence. In addition, this study assessed SQoL, but there are other sexual outcomes, such as sexual distress, that could be assessed. The study also was 
Table 3. Binary and categorical factors associated with sexual quality of life (EHP-30 intercourse subscale)*

\begin{tabular}{|c|c|c|c|c|}
\hline Variable & $\mathrm{n}$ & $\begin{array}{l}\text { EHP-30 intercourse subscale } \\
\text { score, mean } \pm \text { SD }\end{array}$ & Statistic & $P$ value \\
\hline \multicolumn{5}{|l|}{ Current hormonal therapy use } \\
\hline Yes & 45 & $67.0 \pm 22.5$ & $4,585.5$ & .20 \\
\hline No & 232 & $59.8 \pm 29.2$ & & \\
\hline \multicolumn{5}{|c|}{ Previous surgical diagnosis of endometriosis } \\
\hline Yes & 151 & $61.0 \pm 28.3$ & 9,529 & .98 \\
\hline No & 126 & $60.9 \pm 28.4$ & & \\
\hline \multicolumn{5}{|l|}{ Hysterectomy } \\
\hline Yes & 8 & $68.1 \pm 26.2$ & 936 & .53 \\
\hline No & 269 & $60.7 \pm 28.4$ & & \\
\hline \multicolumn{5}{|l|}{ Ethnicity } \\
\hline Caucasian & 200 & $62.7 \pm 26.8$ & 8,474 & .19 \\
\hline Other & 77 & $56.3 \pm 31.5$ & & \\
\hline \multicolumn{5}{|l|}{ Sexual orientation } \\
\hline Heterosexual & 265 & $61.8 \pm 27.8$ & $1,004.5$ & .031 \\
\hline Other & 12 & $41.7 \pm 34.0$ & & \\
\hline \multicolumn{5}{|l|}{ Experience as a child: sexual touch } \\
\hline Yes & 46 & $63.3 \pm 39.7$ & 1.3806 & .50 \\
\hline No & 209 & $59.9 \pm 28.1$ & & \\
\hline Refused to answer & 22 & $65.8 \pm 28.0$ & & \\
\hline \multicolumn{5}{|l|}{ Experience as a child: sexual threat } \\
\hline Yes & 10 & $67.5 \pm 22.9$ & 0.83048 & .66 \\
\hline No & 244 & $60.6 \pm 28.5$ & & \\
\hline Refused to answer & 23 & $64.3 \pm 28.3$ & & \\
\hline \multicolumn{5}{|l|}{ Experience as an adult: sexual assault } \\
\hline Yes & 42 & $63.6 \pm 24.7$ & 1.1683 & .56 \\
\hline No & 215 & $59.9 \pm 29.1$ & & \\
\hline Refused to answer & 20 & $66.5 \pm 27.1$ & & \\
\hline \multicolumn{5}{|l|}{ Married } \\
\hline Yes & 149 & $60 \pm 30.0$ & $9,689.5$ & .82 \\
\hline No & 128 & $62.0 \pm 26.3$ & & \\
\hline \multicolumn{5}{|l|}{ Ever pregnant } \\
\hline Yes & 139 & $60.0 \pm 29.2$ & $9,838.5$ & .71 \\
\hline No & 138 & $61.8 \pm 27.5$ & & \\
\hline \multicolumn{5}{|l|}{ Parity } \\
\hline Parous & 110 & $61.3 \pm 29.7$ & $8,866.5$ & .63 \\
\hline Nulliparous & 167 & $60.7 \pm 27.4$ & & \\
\hline \multicolumn{5}{|l|}{ Education } \\
\hline Some high school & 7 & $69.3 \pm 21.3$ & 16.544 & .011 \\
\hline Graduated high school or GED & 26 & $64.0 \pm 25.3$ & & \\
\hline Some college & 65 & $68.2 \pm 23.7$ & & \\
\hline Graduated 2-y college & 37 & $69.1 \pm 28.0$ & & \\
\hline Graduated 4-y college & 81 & $52.8 \pm 27.8$ & & \\
\hline Postgraduate degree & 54 & $55.0 \pm 33.7$ & & \\
\hline Other & 7 & $70.0 \pm 14.7$ & & \\
\hline \multicolumn{5}{|l|}{ Income } \\
\hline$<\$ 20,000$ & 24 & $69.0 \pm 19.7$ & 7.9312 & .16 \\
\hline$\$ 20,000-\$ 39,999$ & 41 & $61.3 \pm 25.3$ & & \\
\hline$\$ 40,000-\$ 59,999$ & 39 & $67.8 \pm 29.6$ & & \\
\hline$\$ 60,000-\$ 79,999$ & 59 & $59.5 \pm 30.7$ & & \\
\hline$\$ 80,000-\$ 99,999$ & 42 & $53.6 \pm 26.5$ & & \\
\hline$\geq \$ 100,000$ & 72 & $59.8 \pm 30.0$ & & \\
\hline
\end{tabular}


Table 3. Continued

\begin{tabular}{|c|c|c|c|c|}
\hline Variable & $\mathrm{n}$ & $\begin{array}{l}\text { EHP-30 intercourse subscale } \\
\text { score, mean } \pm \text { SD }\end{array}$ & Statistic & $P$ value \\
\hline \multicolumn{5}{|l|}{ Smoke } \\
\hline Yes & 34 & $66.8 \pm 22.9$ & 3,735 & .36 \\
\hline No & 243 & $60.1 \pm 28.9$ & & \\
\hline \multicolumn{5}{|l|}{ Alcohol } \\
\hline Yes & 181 & $58.8 \pm 28.5$ & 9,820 & .074 \\
\hline No & 96 & $65.1 \pm 27.5$ & & \\
\hline \multicolumn{5}{|l|}{ Referral type } \\
\hline New & 226 & $62.5 \pm 28.1$ & 6,837.5 & .037 \\
\hline Rereferral & 51 & $54.1 \pm 28.5$ & & \\
\hline \multicolumn{5}{|c|}{ Abdominal wall pain (Carnett test) } \\
\hline Positive & 82 & $66.8 \pm 24.0$ & 6,787.5 & .047 \\
\hline Negative & 195 & $58.5 \pm 29.6$ & & \\
\hline \multicolumn{5}{|c|}{ Pelvic floor myalgia } \\
\hline Yes & 93 & $73.4 \pm 20.7$ & $5,400.5$ & $<.0001$ \\
\hline No & 184 & $54.6 \pm 29.6$ & & \\
\hline \multicolumn{5}{|c|}{ ASRM endometriosis stage } \\
\hline$|-| \mid$ & 177 & $64.2 \pm 26.1$ & 5.9786 & .050 \\
\hline III-IV & 97 & $54.6 \pm 31.5$ & & \\
\hline Missing & 3 & $71.7 \pm 2.9$ & & \\
\hline \multicolumn{5}{|c|}{ Irritable bowel syndrome } \\
\hline Yes & 152 & $62.8 \pm 26.5$ & 8,945 & .40 \\
\hline No & 125 & $58.7 \pm 30.3$ & & \\
\hline \multicolumn{5}{|c|}{ Bladder pain syndrome } \\
\hline Yes & 140 & $67.6 \pm 25.6$ & $7,104.5$ & $<.001$ \\
\hline No & 137 & $54.2 \pm 29.4$ & & \\
\hline
\end{tabular}

ASRM = American Society for Reproductive Medicine; EHP-30 = Endometriosis Health Profile-30; GED = Graduate Equivalency Diploma.

*277 informative observations for all considered variables.

conducted at a tertiary referral center, which can affect generalizability of our results to other settings.

The association between deep dyspareunia and worse SQoL suggests that treatment of deep dyspareunia could be important in improving SQoL in women with endometriosis, independent

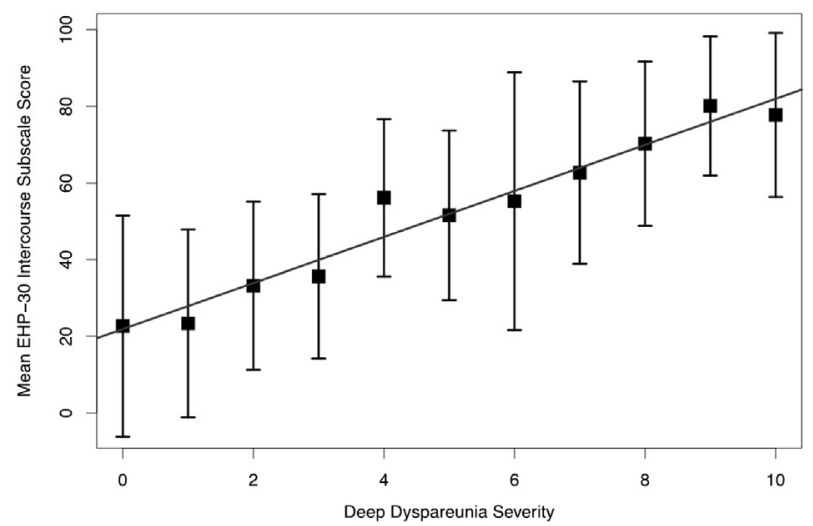

Figure 2. Correlation between deep dyspareunia severity and worse sexual quality of life (higher EHP-30 intercourse subscale score; $r=0.55, P<.0001$ ). Error bars indicate the mean and SD in EHP-30 intercourse subscale score. EHP-30 = Endometriosis Health Profile-30. of superficial dyspareunia or psychological comorbidities. It is noteworthy that deep dyspareunia and superficial dyspareunia were associated with SQoL, suggesting that each affects SQoL in a different manner and to a different degree. Concurrent deep and superficial dyspareunia is not uncommon ${ }^{2}$ and our results indicated that deep and superficial dyspareunia independently contributed to worse SQoL.

Depression and pain catastrophizing were associated with worse SQoL in our study. It is known that pain catastrophizing and depression are associated with chronic pain severity and negatively affect QoL. ${ }^{38,39}$ Depression has been associated with SQoL in terms of sexual desire, sexual arousal, sexual cognition, and orgasmic functions. ${ }^{40}$ Conversely, struggles with sexual function could result in depression symptoms. ${ }^{41}$ Pain catastrophizing is another cognitive process that warrants more investigation for its role in SQoL. Some studies have found pain catastrophizing to be associated with lower overall $\mathrm{QoL}^{42,43}$; however, the association between pain catastrophizing and SQoL has been underinvestigated. ${ }^{44}$

Our results showed an association between SQoL and bladder pain syndrome. Bladder pain syndrome has been independently associated with severity of chronic pelvic pain. ${ }^{20}$ Concurrent endometriosis and bladder pain syndrome also have implications 
Table 4. Factors independently associated with worse sexual quality of life using minimization of Akaike information criterion*

\begin{tabular}{|c|c|c|}
\hline Variable & $\beta$ coefficient $^{\dagger}(95 \% \mathrm{CI})$ & $P$ value \\
\hline $\begin{array}{l}\text { Deep dyspareunia severity } \\
\quad(0-10)^{\ddagger}\end{array}$ & $4.50(3.55-5.45)$ & $<.0001$ \\
\hline $\begin{array}{l}\text { Superficial dyspareunia } \\
\text { severity }(0-10)^{\ddagger}\end{array}$ & $1.92(1.05-2.78)$ & $<.0001$ \\
\hline $\begin{array}{l}\text { Depression (PHQ-9) score } \\
\quad(0-27)^{\ddagger}\end{array}$ & $0.86(0.42-1.30)$ & .00015 \\
\hline $\begin{array}{l}\text { Pain Catastrophizing Scale } \\
\text { score }(0-52)^{\ddagger}\end{array}$ & $0.22(0.01-0.43)$ & .043 \\
\hline $\begin{array}{l}\text { Bladder pain syndrome } \\
\text { diagnosis (yes) }\end{array}$ & 5.69 (0.75-10.64) & .024 \\
\hline $\begin{array}{l}\text { Sexual orientation } \\
\quad \text { (heterosexual) }\end{array}$ & 19.95 (8.16-31.74) & .00098 \\
\hline Referral type (rereferral) & $-7.34(-13.58$ to -1.09$)$ & .022 \\
\hline
\end{tabular}

$\mathrm{PHQ}=$ Patient Health Questionnaire.

*277 informative observations for all considered variables.

${ }^{\dagger} \beta$ Coefficient from regression model.

${ }^{\ddagger}$ Continuous variable.

§Binary variable (yes vs no [reference]).

"Binary variable (heterosexual vs other sexual orientation [reference]).

"Binary variable (rereferral vs new referral [reference]).

for sexual pain. ${ }^{45-47}$ Bladder pain syndrome could be a marker of central sensitization, ${ }^{20}$ a process involving central nervous system mechanisms that amplify pain, ${ }^{48}$ and has been found in women with endometriosis. ${ }^{49}$ It is interesting that the association with SQoL is specific to bladder pain syndrome rather than irritable bowel syndrome. This suggests a specific importance of the bladder in sexual pain compared with functional abnormalities of the bowel.

Our finding of worse SQoL in women with heterosexual orientation requires further studies. We could not assess whether it might be because opposite-sex couples were more likely to involve penetration during sexual activity or because pain with penetration might have a different meaning for opposite-sex couples compared with same-sex couples. New referrals also had worse SQoL compared with rereferrals. This is a surprising observation because rereferrals to the center would have failed previous treatment, although it is possible that rereferrals were primarily re-referred for chronic pelvic pain recurrences rather than for worsening sexual pain.

Furthermore, it should be emphasized that although we studied deep dyspareunia in women with endometriosis, the deep dyspareunia symptom itself might be directly due to endometriosis in some cases, but in other cases it actually might be due to other conditions (eg, depression or bladder pain syndrome) comorbid in a patient with endometriosis. More acute causes of deep dyspareunia also can be present in women with endometriosis (eg, salpingitis or cervicitis), but such patients were excluded from this study. For women in whom deep dyspareunia might be due directly to endometriosis, our study suggests that treatment of endometriosis (eg, surgery or hormonal) could lead to improvement of SQoL, independent of treatments for superficial dyspareunia or comorbid conditions. We are currently following this cohort over 3 years to determine the impact of endometriosis treatments on long-term pain and QoL outcomes.

\section{CONCLUSIONS}

In summary, more severe deep dyspareunia was found to be associated with worse SQoL in women with endometriosis independent of other pain severities, psychological comorbidities, pain diagnoses, and demographic and behavioral factors. We previously proposed a framework for deep dyspareunia in endometriosis that encompasses disease-specific factors, concurrent diagnoses (eg, bladder pain syndrome), psychological comorbidities (eg, depression), and central sensitization. ${ }^{9}$ This study confirms that these latter factors also are important for SQoL. To address these multifactorial factors, ${ }^{45}$ a multidisciplinary approach has been proposed for treatment of sexual dysfunction in endometriosis.?

Corresponding Author: Paul J. Yong, MD, PhD, FRCSC, BC Women's Center for Pelvic Pain and Endometriosis, F2, 4500 Oak Street, Vancouver, BC, Canada V6H 3N1. Tel: 1-604-8752534; Fax: 1-604-875-2569; E-mail: paul.yong@vch.ca

Conflicts of Interest: Authors report no conflict of interest.

Funding: This project was supported by a Canadian Institutes of Health Research (CIHR) Operating Grant Priority Announcement (Reproductive \& Child Health Start-up Grant) from the Institute of Human Development, Child and Youth Health (IHD-137431) and a CIHR Transitional Open Operating Grant (MOP-142273). This work also was supported by the BC Women's Hospital and the Women's Health Research Institute, a VCHRI Investigator Award from the VGH and UBC Hospital Foundation (Mentored Clinician Scientist Award to P.J.Y.), and a Scholar Award from the Michael Smith Foundation for Health Research (to S.K.L.).

\section{STATEMENT OF AUTHORSHIP}

\section{Category 1}

(a) Conception and Design

Paul J. Yong

(b) Acquisition of Data

Leona K. Shum; Mohamed A. Bedaiwy; Catherine Allaire; Christina Williams; Heather Noga; Paul J. Yong

(c) Analysis and Interpretation of Data Leona K. Shum; Arianne Albert; Paul J. Yong

\section{Category 2}

(a) Drafting the Article Leona K. Shum 
(b) Revising It for Intellectual Content Mohamed A. Bedaiwy; Catherine Allaire; Christina Williams; Heather Noga; Arianne Albert; Sarka Lisonkova; Paul J. Yong

\section{Category 3}

(a) Final Approval of the Completed Article Leona K. Shum; Mohamed A. Bedaiwy; Catherine Allaire; Christina Williams; Heather Noga; Arianne Albert; Sarka Lisonkova; Paul J. Yong

\section{REFERENCES}

1. Jarząbek-Bielecka G, Radomski D, Pawlaczyk M, et al. Dyspareunia as a sexual problem in women with endometriosis. Arch Perinat Med 2010;16:51-53.

2. Yong PJ, Sadownik L, Brotto LA. Concurrent deepsuperficial dyspareunia: prevalence, associations, and outcomes in a multidisciplinary vulvodynia program. J Sex Med 2015;12:219-227.

3. Denny E, Mann CH. Endometriosis-associated dyspareunia: the impact on women's lives. J Fam Plan Reprod Heal Care 2007;33:189-193.

4. Ferrero S, Esposito F, Abbamonte LH, et al. Quality of sex life in women with endometriosis and deep dyspareunia. Fertil Steril 2005;83:573-579.

5. Lukic A, Di Properzio M, De Carlo S, et al. Quality of sex life in endometriosis patients with deep dyspareunia before and after laparoscopic treatment. Arch Gynecol Obstet 2016; 293:583-590.

6. Fritzer N, Tammaa A, Haas D, et al. When sex is not on fire: a prospective multicentre study evaluating the short-term effects of radical resection of endometriosis on quality of sex life and dyspareunia. Eur J Obstet Gynecol Reprod Biol 2016; 197:36-40.

7. Melis I, Litta P, Nappi L, et al. Sexual function in women with deep endometriosis: correlation with quality of life, intensity of pain, depression, anxiety, and body image. Int $J$ Sex Heal 2015;27:175-185.

8. Eskenazi B, Warner ML. Epidemiology of endometriosis. Obstet Gynecol Clin North Am 1997;24:235-258.

9. Yong PJ. Deep dyspareunia in endometriosis: a proposed framework based on pain mechanisms and genito-pelvic pain penetration disorder. Sex Med Rev 2017;5:495-507.

10. Flynn KE, Lin L, Bruner DW, et al. Sexual satisfaction and the importance of sexual health to quality of life throughout the life course of U.S. adults. J Sex Med 2016;13:1642-1650.

11. Vercellini $P$, Somigliana $E$, Buggio $L$, et al. "I can't get no satisfaction": deep dyspareunia and sexual functioning in women with rectovaginal endometriosis. Fertil Steril 2012; 98:1503-1511.el.

12. Ferrero S, Abbamonte LH, Giordano M, et al. Deep dyspareunia and sex life after laparoscopic excision of endometriosis. Hum Reprod 2007;22:1142-1148.

13. Tripoli TM, Sato H, Sartori MG, et al. Evaluation of quality of life and sexual satisfaction in women suffering from chronic pelvic pain with or without endometriosis. J Sex Med 2011; 8:497-503.
14. Jones G, Kennedy S, Barnard A, et al. Development of an endometriosis quality-of-life instrument: the Endometriosis Health Profile-30. Obstet Gynecol 2001;98:258-264.

15. Fritzer N, Haas D, Oppelt $P$, et al. More than just bad sex: sexual dysfunction and distress in patients with endometriosis. Eur J Obstet Gynecol Reprod Biol 2013;169:392-396.

16. Brotto LA, Yong P, Smith KB, et al. Impact of a multidisciplinary vulvodynia program on sexual functioning and dyspareunia. J Sex Med 2015;12:238-247.

17. Jones G, Jenkinson C, Kennedy S. Evaluating the responsiveness of the endometriosis health profile questionnaire: the EHP-30. Qual Life Res 2004;13:705-713.

18. Jones G, Jenkinson C, Taylor N, et al. Measuring quality of life in women with endometriosis: tests of data quality, score reliability, response rate and scaling assumptions of the Endometriosis Health Profile Questionnaire. Hum Reprod 2006;21:2686-2693.

19. Yong P, Williams C, Houlihan E, et al. Development of a centre for interdisciplinary care of patients with pelvic pain and endometriosis. B C Med J 2013;55:244-247.

20. Yosef A, Allaire C, Williams C, et al. Multifactorial contributors to the severity of chronic pelvic pain in women. Am J Obstet Gynecol 2016;215:760.el-760.e14.

21. Harris PA, Taylor R, Thielke R, et al. Research Electronic Data Capture (REDCap)-a metadata-driven methodology and workflow process for providing translational research informatics support. J Biomed Inform 2009;42:377-381.

22. Streuli I, Gaitzsch H, Wenger J, et al. Endometriosis after menopause: physiopathology and management of an uncommon condition. Climacteric 2017;20:138-143.

23. Becker CM, Laufer MR, Stratton P, et al. World Endometriosis Research Foundation Endometriosis Phenome and Biobanking Harmonisation Project: I. Surgical phenotype data collection in endometriosis research. Fertil Steril 2014;102:1213-1222.

24. Kroenke K, Spitzer RL, Williams JB. The PHQ-9: validity of a brief depression severity measure. J Gen Intern Med 2001; 16:606-613.

25. Spitzer RL, Kroenke K, Williams JBW, et al. Brief measure for assessing generalized anxiety disorder. Arch Intern Med 2006;166:1092-1097.

26. Osman A, Barrios FX, Kopper BA, et al. Factor structure, reliability, and validity of the pain catastrophizing scale. J Behav Med 1997;20:589-605.

27. Suleiman S, Johnston DE. The abdominal wall: an overlooked source of pain. Am Fam Physician 2001;64:431-438.

28. Drossman DA. The functional gastrointestinal disorders and the Rome III process. Gastroenterology 2006;130:1377-1390.

29. Meijlink JM. Interstitial cystitis and the painful bladder: a brief history of nomenclature, definitions and criteria. Int J Urol 2014;21:4-12.

30. Warren JW, Meyer WA, Greenberg P, et al. Using the International Continence Society's definition of painful bladder syndrome. Urology 2006;67:1138-1142. 
31. Bernstein DP, Fink L, Handelsman L, et al. Initial reliability and validity of a new retrospective measure of child abuse and neglect. Am J Psychiatry 1994;151:1132-1136.

32. Revised American Society for Reproductive Medicine classification of endometriosis: 1996. Fertil Steril 1997;67:817-821.

33. Venables WN, Ripley BD. Modern applied statistics with S. 4th ed. New York: Springer-Verlag; 2002.

34. Vittinghoff E, Glidden DV, Shiboski SC, et al. Regression methods in biostatistics. 2nd ed. New York: Springer-Verlag; 2012.

35. Burnham KP, Anderson DR. Model selection and multimodel inference: a practical information-theoretic approach. 2nd ed. New York: Springer-Verlag; 2002.

36. Burnham KP, Anderson DR. Multimodel inference: understanding AIC and BIC in model selection. Sociol Methods Res 2004;33:261-304.

37. Schönbrodt FD, Perugini M. At what sample size do correlations stabilize? J Res Pers 2013;47:609-612.

38. Edwards RR, Calahan C, Mensing G, et al. Pain, catastrophizing, and depression in the rheumatic diseases. Nat Rev Rheumatol 2011;7:216-224.

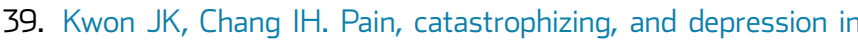
chronic prostatitis/chronic pelvic pain syndrome. Int Neurourol J 2013;17:48-58.

40. Cyranowski JM, Frank E, Cherry C, et al. Prospective assessment of sexual function in women treated for recurrent major depression. J Psychiatr Res 2004;38:267-273.

41. Jia SZ, Leng JH, Shi J, et al. Health-related quality of life in women with endometriosis: a systematic review. J Ovarian Res 2012;5:1-9.
42. Martin CE, Johnson E, Wechter ME, et al. Catastrophizing: a predictor of persistent pain among women with endometriosis at 1 year. Hum Reprod 2011;26:3078-3084.

43. Carey ET, Martin CE, Siedhoff MT, et al. Biopsychosocial correlates of persistent postsurgical pain in women with endometriosis. Int J Gynecol Obstet 2014;124:169-173.

44. De Graaff AA, Van Lankveld J, Smits LJ, et al. Dyspareunia and depressive symptoms are associated with impaired sexual functioning in women with endometriosis, whereas sexual functioning in their male partners is not affected. Hum Reprod 2016;31:2577-2586.

45. Pluchino $N$, Wenger $J M$, Petignat $P$, et al. Sexual function in endometriosis patients and their partners: effect of the disease and consequences of treatment. Hum Reprod Update 2016;22:762-774.

46. Cervigni M, Natale F. Gynecological disorders in bladder pain syndrome/interstitial cystitis patients. Int J Urol 2014; 21:85-88.

47. Yong PJ, Mui J, Allaire $C$, et al. Pelvic floor tenderness in the etiology of superficial dyspareunia. J Obstet Gynaecol Can 2014;36:1002-1009.

48. He W, Liu X, Zhang Y, et al. Generalized hyperalgesia in women with endometriosis and its resolution following a successful surgery. Reprod Sci 2010;17:1099-1111.

49. Bajaj P, Bajaj P, Madsen $H$, et al. Endometriosis is associated with central sensitization: a psychophysical controlled study. J Pain 2003;4:372-380. 